\section{Os Destinos da SBEM: Olhando Prá Trás.. e Prá Frente}

A SBEM vive um grande momento. Começa seu 53‥ ano em uma posição bastante confortável, mas ainda se move para o futuro com grandes expectativas. E nada disso foi por acaso. As gestões anteriores trabalharam muito para levá-la a um patamar onde todos os sócios se sentissem motivados e orgulhosos. Pois estamos.

A credibilidade pública conquistada pela SBEM tem garantido sua presença e influência em variados plenários de atuação da classe médica, como tem permitido parcerias crescentes com os patrocinadores habituais, que explicam sua sólida posição fiscal e administrativa. As Regionais se tornaram ainda mais dinâmicas e atuantes, congregando mais intensamente seus associados locais. Por sua vez, a multiplicidade de eventos científicos realizados sob o âmbito da SBEM constitui um forte, talvez o maior, estímulo à participação e satisfação de todos.

$\mathrm{N}$ ão obstante toda essa evolução, a endocrinologia brasileira ainda enfrenta muitos desafios hoje, e outros precisarão ser enfrentados em futuro próximo. Para responder a essas demandas, uma sociedade médica precisa ter recursos, precisa ser organizada com boa infra-estrutura e precisa ser hábil e ágil para identificar e resolver problemas. A SBEM tem evoluído com estas características, mas, para isso, também ela própria tem se transformado continuamente. Qualificar ainda mais seus serviços e ampliar sua exposição pública continuarão a ser itens prioritários da nossa agenda. Como exemplo de inovações, estão se implementando atividades cooperativas com sociedades afins, tanto nacionais quanto internacionais. Entre estas se desenvolve uma promissora interação com a Endocrine Soci ety e firmam-se parcerias com a A merican A ssociation of Clinical Endocrinologists e a I nternational Society of Endocrinology.

$\mathrm{N}$ os próximos dois anos a SBEM se orientará preferencialmente para a obtenção de cinco metas principais. A primeira será uma ampla e profunda R eforma dos Estatutos para incorporar inúmeras demandas e exigências dos novos tempos, que incluem maior democratização do processo de renovação de seus dirigentes, incorporação do Projeto de Diretrizes da AM B/ CFM e criação de novos D epartamentos, entre os quais o de Informática e D ivulgação e o de D efesa Profissional. Em segundo lugar, implementaremos o processo de R evali dação do Título de Especialista, em consonância com normas da AM B/ CFM para viger a partir de 2004, assim como nos empenharemos para ampliar a abrangência e a importância do título conferido pela SBEM. U m robusto Programa de Educação M édica Continuada, liderado pelos respectivos Departamentos e executados homogeneamente pelas Regionais, permitirá uma reciclagem uniforme e simultânea em todo o país, em complementação ao calendário regular de eventos científicos maiores de nossa Sociedade. A pontuação conferida por este programa contará para a revalidação da titulação, alternativamente às provas tradicionais. I mportante salientar que neste contexto, os Departamentos ficarão ainda mais fortalecidos e valorizados, porque estarão à frente da redação das novas D iretrizes que servirão de orientação para editorial

\author{
Valéria Guimarães
}

Presidente-eita, SBEM (2003-2004) 
médicos endocrinologistas e não-especialistas, e serão utilizadas como normatização e fonte oficial de informações pelo M inistério da Saúde. Faremos ainda uma maior diversificação da Campanha de Valorização do Endocrinologista, cuja repercussão tem sido expressiva e sensivelmente produtiva. Enfim, caminharemos para uma maior Profissionalização A dministrativa de nossa Sociedade, envolvendo gerenciamentos nas áreas contábil, jurídica e de marketing comercial. U m ambicioso projeto de divulgação e valorização da marca SBEM está sendo elaborado e certamente será um dos pontos fortes deste período.

Como a comunidade endocrinológica brasileira tem crescido continuamente, a SBEM vem incorporando, cada vez mais, novos endocrinologistas com diferentes áreas de interesse e atuação. M uitos destes colegas estão eventualmente vinculados a outras sociedades que também representam seus interesses, mas os recursos e a influência da SBEM proporcionam benefícios aos seus membros que não podem ser assegurados por sociedades de super-especialidades. A SBEM representa, pois, uma harmônica coalizão de endocrinologistas agregados em seus diversos $D$ epartamentos e é muito importante que ela represente bem e cada vez melhor os interesses de cada grupo. $M$ as a chave do sucesso da atuação de to dos os $D$ epartamentos é a participação efetiva de seus membros e esta será grandemente estimulada.

U m patrimônio do qual a SBEM muito se orgulha é a nossa revista A rquivos Brasileiros de Endo- crinologia \& Metabologia. Os ABE\&M nasceram com o empenho editorial de Waldemar Berardinelli, mas cresceram continuamente e alcançou um estágio de superior qualidade e importância sob a liderança de Claudio Elias Kater. Os ABE\&M continuarão a publicar e repercutir o melhor da endocrinologia nacional disponível.

Agora olhando para os lados, a SBEM-Regional do Distrito Federal tem vivido uma fase de grande crescimento, muitas atividades e marcantes conquistas. Com o decisivo apoio da SBEM-N acional, nas Presidências de João $\mathrm{H}$ amilton Romaldini e Amélio $\mathrm{F}$. de Godoy $M$ atos, e com a participação ativa dos nossos sócios, deflagraram-se várias campanhas públicas locais, com grande repercussão e impacto na relação da endocrinologia com a comunidade. U m projeto editorial (I nformativo SBEM-DF) expôs os endocrinologistas brasilienses aos colegas de outras especialidades e promoveu sua interlocução com os demais endocrinologistas brasileiros. I sto habilitou a SBEM -DF para a tarefa de realizar o 25․ C ongresso Brasileiro de Endocrinologia e Metabologia em Setembro passado, um evento que refletiu toda a exuberância científica e a tradição fraternal de nossa Sociedade. Nosso 250. CBEM mereceu o editorial do informativo de D ezembro da Endocrine Society.

Em nome da SBEM-DF registro minha satisfação com a oportunidade de servir à SBEM como sua Presidente no período de 2003-2004. Verdadeiramente, uma honra e um privilégio. 